\section{Aspectos clínicos e moleculares do hipogonadismo hipogonadotrófico isolado congênito}

\author{
Clinical and molecular aspects of congenital \\ isolated hypogonadotropic hypogonadism
}

Cintia Tusset', Éricka B. Trarbach', Letícia Ferreira Gontijo Silveira', Daiane Beneduzzi', Luciana Montenegro', Ana Claudia Latronico'

\section{SUMÁRIO}

O hipogonadismo hipogonadotrófico isolado ( $\mathrm{HHI}$ ) congênito caracteriza-se pela falta completa ou parcial de desenvolvimento puberal em decorrência de defeitos na migração, síntese, secreção ou ação do hormônio liberador de gonadotrofinas ( $\mathrm{GRH})$. Baixas concentrações de esteroides sexuais e valores reduzidos ou inapropriadamente normais de gonadotrofinas hipofisárias (LH e FSH) definem, do ponto de vista laboratorial, essa condição clínica. A secreção dos demais hormônios hipofisários encontra-se normal, bem como a ressonância magnética de região hipotalâmica-hipofisária, demonstrando a ausência de uma causa anatômica. Alterações olfatórias, como anosmia ou hiposmia, podem estar associadas ao $\mathrm{HHI}$, caracterizando a síndrome de Kallmann. Uma lista crescente de genes está envolvida na etiologia do HHI, sugerindo a heterogeneidade e a complexidade da base genética dessa condição. Distúrbios na rota de migração dos neurônios secretores de $\mathrm{GnRH}$ e dos neurônios olfatórios formam a base clínico-patológica da síndrome de Kallmann. Mutações nos genes KAL1, FGFR1/FGF8, PROK2/ PROKR2, NELF, CHD7, HS6ST1 e WDR11 foram associadas a defeitos de migração neuronal, causando a síndrome de Kallmann. É notável que defeitos nos genes FGFR1, FGF8, PROKR2, CHD7 e WDR11 foram também associados ao $\mathrm{HHI}$ sem alterações olfatórias (HHI normósmico), porém em menor frequência. Adicionalmente, defeitos nos KISS1R, TAC3/TACR3 e GNRH1/GNRHR foram descritos exclusivamente em pacientes com HHI normósmico. Neste trabalho, revisaremos as características clínicas, hormonais e genéticas do HHI. Arq Bras Endocrinol Metab. 2011;55(8):501-11

\section{Descritores}

Hipogonadismo hipogonadotrófico isolado normósmico; síndrome de Kallmann; GnRH; mutações

\section{SUMMARY}

Congenital isolated hypogonadotropic hypogonadism $(\mathrm{IHH})$ is characterized by partial or complete lack of pubertal development due to defects in migration, synthesis, secretion or action of gonadotropin-releasing hormone $(\mathrm{GnRH})$. Laboratory diagnosis is based on the presence of low levels of sex steroids, associated with low or inappropriately normal levels of pituitary gonadotropins ( $\mathrm{LH}$ and FSH). Secretion of other pituitary hormones is normal, as well magnetic resonance imaging of the hypothalamohypophyseal tract, which shows absence of an anatomical defects. When IHH is associated with olfactory abnormalities (anosmia or hyposmia), it characterizes Kallmann syndrome. A growing list of genes is involved in the etiology of IHH, suggesting the heterogeneity and complexity of the genetic bases of this condition. Defects in olfactory and $\mathrm{GnRH}$ neuron migration are the etiopathogenic basis of Kallmann syndrome. Mutations in KAL1, FGFR1/FGF8, PROK2/PROKR2, NELF, CHD7, HS6ST1 and WDR11 are associated with defects in neuronal migration, leading to Kallmann syndrome. Notably, defects in FGFR1, FGF8, PROKR2, CHD7 and WDR11 are also associated with $\mathrm{IHH}$, without olfactory abnormalities (normosmic $\mathrm{IHH}$ ), although in a lower frequency. Mutations in KISS1R, TAC3/TACR3 and GNRH1/GNRHR are described exclusively in patients with normosmic $\mathrm{IHH}$. In this paper, we reviewed the clinical, hormonal and genetic aspects of IHH. Arq Bras Endocrinol Metab. 2011;55(8):501-11
${ }^{1}$ Unidade de Endocrinologia do Desenvolvimento, Laboratório de Hormônios e Genética Molecular LIM/42, Divisão de Endocrinologia e Metabologia, Hospital das Clínicas, Faculdade de Medicina da Universidade de São Paulo (HC-FMUSP), São Paulo, SP, Brasil

Correspondência para: Ana Claudia Latronico

Av. Dr. Enéas de Carvalho Aguiar, 155 $2^{\circ}$ andar, bloco 6 05403-900 - São Paulo, SP, Brasil anacl@usp.br

Recebido em 14/Set/2011 Aceito em 21/Out/2011

Keywords

Normosmic isolated hypogonadotropic hypogonadism; Kallmann syndrome; GnRH; mutations 


\section{INTRODUÇÃO}

$\mathrm{O}$ desenvolvimento puberal normal é dependente da secreção e da ação adequada do hormônio liberador de gonadotrofinas $(\mathrm{GnRH})$. O GnRH é produzido por um pequeno número de neurônios secretores de GnRH situados no hipotálamo ventromedial. O GnRH controla a secreção hipofisária das gonadotrofinas, hormônio folículo-estimulante (FSH) e hormônio luteinizante $(\mathrm{LH})$, as quais estimulam a esteroidogênese e a gametogênese nas gônadas, culminando com o desenvolvimento dos caracteres sexuais secundários e aquisição da capacidade reprodutiva. Em primatas, o eixo hipotálamo-hipófise-gonadal é ativo durante o período neonatal, seguido por um período de relativa quiescência durante toda a infância. A reemergência dos pulsos secretores de GnRH ocorre no final da infância e coincide com o início do período puberal (1).

Os neurônios secretores de GnRH são os únicos entre os neurônios hipotalâmicos que têm sua origem fora do sistema nervoso central. Esses neurônios são formados por células progenitoras do epitélio nasal na placa olfatória e migram em associação com os neurônios olfatórios até alcançar a placa crivosa (2). Na placa crivosa, as fibras olfatórias unem-se aos primórdios do bulbo olfatório, enquanto os neurônios secretores de GnRH atravessam essa estrutura até alcançar o hipotálamo. Finalmente, os neurônios secretores de GnRH projetam seus axônios na eminência média hipotalâmica para que ocorra a secreção do GnRH (2). Nos seres humanos, a migração dos neurônios secretores de GnRH começa na $6^{\mathrm{a}}$ semana do desenvolvimento embrionário, sendo estes observados no hipotálamo fetal na $9^{\mathrm{a}}$ a $10^{\mathrm{a}}$ semana. Por volta da $14^{\mathrm{a}}$ a $16^{\mathrm{a}}$ semana de gestação, esses neurônios já estão conectados ao sistema porta-hipofisário, completando, assim, seu desenvolvimento e maturação (3).

A complexa organização e regulação do eixo hipotálamo-hipófise-gonadal humano torna-o suscetível a diversas disfunções, visto o grande número de alterações genéticas identificadas em proteínas reguladoras desse eixo, as quais levam a graus variáveis de hipogonadismo hipogonadotrófico isolado (HHI) congênito (Figura l e Tabela 1) (4). Além disso, o diagnóstico genético de pacientes com desenvolvimento puberal ausente ou incompleto devido à deficiência gonadotrófica levou à identificação de novas causas genéticas associadas à etiologia do HHI (5-11). Modelos de heranças digênicas e oligogênicas da deficiência da secreção de

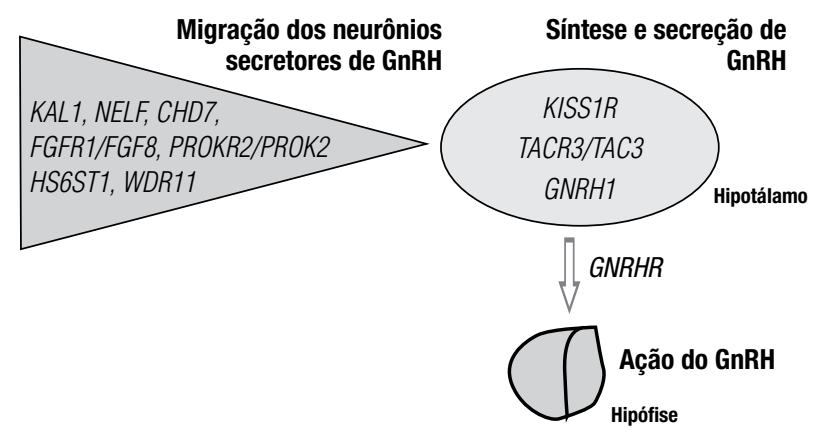

Figura 1. Genes envolvidos com a etiologia do hipogonadismo hipogonadotrófico isolado congênito e síndrome de Kallmann.

$\mathrm{GnRH}$ foram descritos, frequentemente associados a fenótipos reprodutivos variáveis dentro de uma família com padrão de herança não nendeliano (4). Dessa forma, torna-se fundamental a atualização periódica sobre a base genética dos distúrbios puberais. Neste trabalho, revisaremos as características clínicas e hormonais dos pacientes com HHI e os principais genes atualmente associados com o desenvolvimento e a migração dos neurônios secretores de GnRH, assim como na síntese, secreção e ação desse hormônio.

\section{CARACTERÍSTICAS CLÍNICAS E HORMONAIS DO HIPOGONADISMO HIPOGONADOTRÓFICO ISOLADO NORMÓSMICO E DA SÍNDROME DE KALLMANN}

O HHI congênito é definido pela ausência parcial ou completa de desenvolvimento puberal, secundário a um defeito na produção ou na secreção hipotalâmica de GnRH ou pela resistência hipofisária à ação do GnRH (12). O diagnóstico de hipogonadismo é suspeitado diante da ausência ou parada de desenvolvimento puberal após os 18 anos em meninos e 16 anos em meninas. O HHI é caracterizado por baixas concentrações de esteroides sexuais (testosterona ou estradiol) associados a valores baixos ou inapropriadamente normais de gonadotrofinas ( $\mathrm{LH} \mathrm{e} \mathrm{FSH).} \mathrm{Os} \mathrm{pacientes} \mathrm{podem} \mathrm{apresentar}$ resposta ausente, parcial ou normal ao estímulo agudo com GnRH, e a dosagem seriada de LH pode revelar ausência de pulsos ou a presença de pulsos endógenos de LH de baixa frequência e amplitude, demonstrando a variabilidade do grau de acometimento da deficiência de GnRH $(10,13)$. A secreção dos demais hormônios hipofisários encontra-se normal, bem como a ressonância magnética de região hipotalâmica-hipofisária, demonstrando a ausência de uma causa anatômica (12). Em $50 \%$ a $60 \%$ dos casos, o HHI encontra-se associa- 
do a alterações olfatórias como anosmia ou hiposmia, caracterizando a síndrome de Kallmann (12,14,15). O HHI é considerado uma condição clínica rara e geneticamente heterogênea, podendo se manifestar de forma esporádica ou ser herdada como um traço autossômico dominante, recessivo ou, no caso da síndrome de Kallmann, também recessivo ligado ao X (15).

O diagnóstico do HHI congênito é tipicamente realizado durante a segunda ou terceira década de vida, quando os indivíduos afetados apresentam-se com retardo do desenvolvimento puberal. Os pacientes apresentam, em geral, estatura normal ou alta com proporções eunucoides devido ao atraso no fechamento das epífises ósseas, secundário à deficiência de esteroides sexuais, e consequente crescimento linear contínuo dos ossos longos. O fenótipo reprodutivo pode variar de hipogonadismo parcial a completo. Ao exame físico, os pacientes do sexo masculino apresentam frequentemente testículos de tamanho reduzido para a idade, micropênis e escassez de pelos corporais. Criptorquidismo unilateral ou bilateral é um achado frequente, mais comumente visto na síndrome de Kallmann (50\% a $70 \%$ dos casos) do que no HHI normósmico $(20 \%$ a $25 \%$ dos casos $)(15,16)$. A ocorrência de micropênis e criptorquidismo sugere falência da ativação do eixo gonadotrófico na segunda metade da gestação e no período neonatal, fases nas quais ocorre maior crescimento peniano (17). A pubarca pode ocorrer espontaneamente, porém costuma ter desenvolvimento parcial ou tardio. Ginecomastia não é frequente, estando presente em cerca de $20 \%$ dos casos, porém sua incidência pode aumentar com o início da reposição de testosterona. As mulheres apresentam-se com queixa de amenorreia primária e desenvolvimento mamário parcial ou ausente e a ultrassonografia pélvica revela volume uterino e ovariano reduzido para a idade. Pubarca e telarca espontâneas são observadas em cerca de $88 \%$ e $50 \%$ das mulheres afetadas, respectivamente, e 10\% apresentam um ou dois episódios de menstruação, antes de evoluir para amenorreia definitiva (18).

Outros estigmas fenotípicos não reprodutivos podem estar associados à síndrome de Kallmann, com frequência variável. Esses estigmas incluem: malformações renais (hipoplasia ou agenesia renal unilateral), malformações craniofaciais (fenda labial e/ou palatina, palato ogival, hipertelorismo ocular e coloboma), sur-

Tabela 1. Causas genéticas de síndrome de Kallmann (SK) e hipogonadismo hipogonadotrófico isolado (HHI)

\begin{tabular}{|c|c|c|c|c|c|}
\hline Gene & Proteína & Função & Herança & Fenótipo & Estigmas \\
\hline KAL1 & Anosmina-1 & Migração dos neurônios GnRH & Recessiva ligada ao X & SK & $\begin{array}{c}\text { Anosmia, sincinesia bimanual, } \\
\text { agenesia renal }\end{array}$ \\
\hline FGFR1 & $\begin{array}{l}\text { Receptor tipo } 1 \text { do fator de } \\
\text { crescimento dos fibroblastos }\end{array}$ & Migração dos neurônios GnRH & Autossômica dominante & $\mathrm{SK} / \mathrm{HHI}$ & $\begin{array}{l}\text { Anosmia, fenda palatina, lábio } \\
\text { Ieporino, agenesia dental }\end{array}$ \\
\hline FGF8 & $\begin{array}{l}\text { Fator de crescimento dos } \\
\text { fibroblastos tipo } 8\end{array}$ & Migração dos neurônios GnRH & Autossômica dominante & $\mathrm{SK} / \mathrm{HHI}$ & $\begin{array}{l}\text { Anosmia, fenda palatina, lábio } \\
\text { leporino, agenesia dental }\end{array}$ \\
\hline PROKR2 & Receptor da procineticina 2 & Migração dos neurônios GnRH & Autossômica recessiva & $\mathrm{SK} / \mathrm{HHI}$ & Anosmia \\
\hline PROK2 & Procineticina 2 & Migração dos neurônios GnRH & Autossômica recessiva & $\mathrm{SK} / \mathrm{HHI}$ & Anosmia \\
\hline NELF & $\begin{array}{c}\text { Fator nasal embrionário do } \\
\text { hormônio liberador de hormônio } \\
\text { luteinizante }\end{array}$ & Migração dos neurônios GnRH & Autossômica dominante & $\mathrm{SK} / \mathrm{HHI}$ & Anosmia \\
\hline CHD7 & $\begin{array}{l}\text { Proteína ligadora do } \\
\text { cromodomínio-helicase-DNA } 7\end{array}$ & $\begin{array}{l}\text { Desenvolvimento dos neurônios } \\
\text { GnRH }\end{array}$ & Autossômica dominante & $\mathrm{SK} / \mathrm{HHI}$ & Síndrome de CHARGE \\
\hline HS6ST1 & $\begin{array}{c}\text { 6-0-sulfotransferase de sulfato de } \\
\text { heparina }\end{array}$ & $\begin{array}{c}\text { Catalisação da transferência de } \\
\text { sulfato na posiçã̃o 6-0 na biogênese } \\
\text { da sulfato de heparina }\end{array}$ & Autossômica dominante? & $\mathrm{SK} / \mathrm{HHI}$ & Palato alto, fenda palatina \\
\hline WDR11 & Proteína WD & Migração dos neurônios GnRH & Autossômica dominante & $\mathrm{SK} / \mathrm{HHI}$ & Anosmia \\
\hline $\begin{array}{l}\text { GPR54/ } \\
\text { KISS1R }\end{array}$ & Receptor da kisspeptina 1 & Estimulação da secreção de GnRH & Autossômica recessiva & $\mathrm{HHI}$ & - \\
\hline TACR3 & Receptor da neurocinina B & Estimulação da secreção de GnRH & Autossômica recessiva & $\mathrm{HHI}$ & - \\
\hline TAC3 & Neurocinina B & Estimulação da secreção de GnRH & Autossômica recessiva & $\mathrm{HHI}$ & - \\
\hline GNRH1 & GnRH & $\begin{array}{l}\text { Síntese de GnRH e sinalização } \\
\text { celular }\end{array}$ & Autossômica recessiva & $\mathrm{HHI}$ & - \\
\hline GNRHR & Receptor de GnRH & $\begin{array}{l}\text { Síntese de GnRH e sinalização } \\
\text { celular }\end{array}$ & Autossômica recessiva & $\mathrm{HHI}$ & - \\
\hline
\end{tabular}


dez neurossensorial, agenesia dental, anomalias digitais (clinodactilia, sindactilia, campilodactilia) e defeitos neurológicos (ataxia cerebelar, anomalias oculomotoras, sincinesia bimanual).

Uma relativa correlação genótipo-fenótipo pode ser observada. As formas de síndrome de Kallmann ligadas ao X, com ou sem mutações no gene $K A L 1$, costumam apresentar fenótipo reprodutivo mais grave e estão particularmente associadas a estigmas como sincinesia bimanual e agenesia renal unilateral, presentes em cerca de $70 \%$ e $30 \%$ dos casos, respectivamente (15). Fenda labial ou palatina parece estar associada a mutações nos genes FGFR I/FGF8. Defeitos em genes envolvidos no controle da produção, secreção e ação do $\mathrm{GnRH}$, como GNRH/GNRHR, KISSIR, TAC3/TACR3, causam HHI exclusivamente normósmico sem associação de outros estigmas não reprodutivos. No entanto, essa aparente correlação genótipo-fenótipo deve ser considerada com ressalvas, já que grande variabilidade inter e intrafamilial foi observada na apresentação clínica em pacientes portadores do mesmo defeito genético $(15,19)$. A análise de familiares afetados pelo HHI demonstrou a presença de pacientes com hipogonadismo completo e parcial, com e sem anosmia e anosmia isolada ou atraso puberal em uma mesma família. Essa variabilidade pode ser parcialmente explicada por fatores ambientais, epigenéticos, ou defeitos associados em mais de um gene (20).

Nos casos com deficiência mais grave de GnRH, a suspeita diagnóstica pode ser aventada na infância, devido à presença de micropênis e criptorquidismo, principalmente na vigência de história de hipogonadismo na família e, no caso da síndrome de Kallmann, outros estigmas associados, como anosmia, sincinesia ou malformações renais (15). Esses casos podem ser confirmados por investigação hormonal antes dos seis meses de idade, período no qual o eixo gonadotrófico ainda está ativado, conhecido como minipuberdade (2l). É importante notar que não há nenhum grau de ambiguidade sexual, mesmo nos pacientes com fenótipo mais grave, pois a masculinização da genitália externa depende da secreção de testosterona secundária ao estímulo das células de Leydig pelo hCG placentário no primeiro trimestre da gestação (22).

A situação oposta, o diagnóstico tardio do HHI congênito, não é uma situação infrequente. Nesses casos os pacientes se apresentam, em geral, com queixas de infertilidade e disfunção sexual. O diagnóstico pode, ainda, ser feito em investigação para condições clínicas comumente associadas, como depressão, falta de energia e fraqueza muscular e osteoporose. Osteoporose é frequente em pacientes que iniciam a reposição hormonal tardiamente e o achado de osteoporose em homens deve chamar atenção para a possibilidade de hipogonadismo (23).

Casos de reversibilidade do HHI congênito foram relatados por vários autores em pacientes com HHIn e síndrome de Kallmann, incluindo pacientes com mutações comprovadamente deletérias nos genes KALl, GnRHR e $F G F R 1(24,25)$. Nesses casos, a reversão do quadro foi atribuída a uma sensibilização e ativação tardia do eixo gonadotrófico após reposição androgênica. Essa variante clínica deve ser suspeitada em pacientes com aumento do volume testicular ao longo do tratamento.

\section{GENES ENVOLVIDOS NA MIGRAÇÃO DOS NEURÔNIOS SECRETORES DE GnRH}

Distúrbios na rota de migração dos neurônios secretores de GnRH e dos neurônios olfatórios formam a base clínico-patológica da síndrome de Kallmann. Esse fato foi confirmado no final da década de 1980, pelo achado anatomopatológico de um emaranhado anormal sobre a placa crivosa, formado pelo acúmulo de neurônios olfatórios e secretores de $\mathrm{GnRH}$ na área superior nasal em um feto de 19 semanas afetado pela síndrome de Kallmann (26). Consequentemente, os genes que codificam proteínas reguladoras do processo migratório dos neurônios secretores de GnRH são apontados como peças-chave no surgimento do HHI associados ou não a anomalias olfatórias.

\section{Gene KAL1}

O primeiro gene causal identificado na síndrome de Kallmann, denominado $K A L 1$, foi mapeado em Xp22.3 $(27,28)$. Esse gene é formado por 14 éxons que codificam a anosmina-1, uma proteína de matriz extracelular de 680 aminoácidos que atua no processo de migração dos neurônios olfatórios e secretores de GnRH (27-29). Durante o desenvolvimento embrionário, a expressão da anosmina- 1 é encontrada no bulbo olfatório, cerebelo, medula, rim e retina (30). A anosmina- 1 é formada por uma região rica em cisteína, um domínio WAP ("whey acidic protein") e quatro repetições de fibronectina tipo III (FNIII), estruturalmente relacionadas às moléculas de adesão celular, e várias regiões de ligação a proteoglicanas sulfato de heparina $(27,28)$. Diferentes 
estudos in vitro têm demonstrado que a anosmina-l é capaz de controlar inúmeras funções celulares, incluindo alongamento de axônios e fasciculação, morfogênese epitelial e atividade migratória de neurônios liberadores de GnRH (31-35). É interessante notar que, apesar de demonstrada a existência da anosmina- $1 \mathrm{em}$ camundongos, o ortólogo do gene $K A L 1$ ainda não foi identificado em roedores (34).

Diversas mutações no gene KALI têm sido descritas em indivíduos com síndrome de Kallmann. Como o KAL1 está localizado na região pseudoautossômica do cromossomo $\mathrm{X}$, as mutações nesse gene são encontradas exclusivamente em pacientes do sexo masculino, podendo ser transmitidas por mulheres portadoras assintomáticas. As mutações no gene $K A L I$ levam à perda de função da anosmina-l e estão amplamente distribuídas ao longo dos seus diferentes domínios proteicos (36). Essas mutações são representadas por deleções completas do gene, deleções intragênicas e alterações de bases. As alterações no gene KALI têm sido identificadas em cerca de 8\%-11\% dos casos esporádicos e 14\%-50\% dos casos familiais de síndrome de Kallmann ligada ao X e não foram associadas a casos de deficiência de GnRH sem alterações olfatórias (36).

\section{Genes FGFR1/FGF8}

O gene do receptor 1 para fator de crescimento de fibroblastos, FGFR-1, também conhecido como KAL2, é formado por 18 éxons e está localizado em 8pl1.2. Esse foi o primeiro gene autossômico relacionado ao surgimento do hipogonadismo hipogonadotrófico em humanos (8). As mutações no FGFRl têm sido encontradas numa prevalência de $10 \%-17 \%$, tanto na síndrome de Kallmann quanto no hipogonadismo hipogonadotrófico normósmico (37). A maior parte dessas mutações foi identificada em heterozigose, sendo representada por pequenas deleções/inserções de base e mutações de ponto (37). Até o momento, existe apenas o relato de uma paciente com hipogonadismo hipogonadotrófico e olfato normal causado por uma deleção em heterozigose completa do gene FGFRI (38).

$O$ receptor tipo 1 do fator de crescimento de fibroblastos (FGFRl) é um membro da superfamília dos receptores tirosina quinase. Mutações inativadoras no FGFRl foram descritas em pacientes com HHI (3941). Dode e cols. (8) sugeriram que a anosmina-1 seria importante na sinalização do FGF e que os produtos dos genes KALI e FGFRI poderiam interagir funcio- nalmente. De fato, foi observado que a anosmina-1 possui sítios de ligação para sulfato de heparina, moléculas importantes na formação do complexo FGF-FGFRl, e que essa proteína pode se ligar com alta afinidade diretamente ao FGFRl, atuando como um coligante modulador do complexo FGFRl-ligante (42). A anosmina-1 é capaz ainda de aumentar a quantidade de sulfato de heparina ligado ao complexo FGFRI-ligante, levando, dessa forma, a um aumento da amplificação de resposta das vias intracelulares mediadas pelo FGFRI (43).

O fator de crescimento de fibroblasto (FGF) 8, um dos ligantes do FGFRl, foi implicado na etiologia do hipogonadismo hipogonadotrófico em humanos. As observações de que o receptor FGFRl contendo a mutação p.L324S exibia um decréscimo específico de afinidade de ligação pelo FGF8 e de que camundongos Fgf8 hipomórficos apresentavam defeitos no desenvolvimento da cavidade nasal e disgenesia de bulbos olfatórios fundamentaram tal hipótese $(41,44)$. Falardeau e cols. (45) e Trarbach e cols. (46) foram os primeiros a descrever mutações no gene $F G F 8$ em pacientes com hipogonadismo hipogonadotrófico. Essas mutações acarretavam a perda de função do FGF8 e foram encontradas tanto em pacientes com síndrome de Kallmann quanto em indivíduos com hipogonadismo hipogonadotrófico normósmico, sugerindo que o decréscimo na sinalização do FGF8 causaria a deficiência de GnRH em humanos. Posteriormente, Chung e cols. (47) avaliaram o desenvolvimento dos neurônios secretores de GnRH em camundongos hipomórficos para os genes FGF8 e FGFR 1, sendo observado que esses fatores comprometem a função do sistema GnRH por ab-rogação da emergência inicial desses neurônios na placa olfatória. Os autores demonstraram ainda que o status heterozigoto do $F g f 8$ é suficiente para causar alterações significativas no desenvolvimento dos neurônios produtores de GnRH (47).

\section{Genes PROKR2 e PROK2}

Diferentes estudos demonstraram que a procineticina $\mathrm{PROK} 2$ e seu receptor acoplado à proteína $\mathrm{G}, \mathrm{O}$ PROKR2, desempenham um papel importante na neurogênese dos bulbos olfatórios no cérebro de mamíferos. Matsumoto e cols. (48) descreveram camundongos knockout Prokr2-/- com hipogonadismo e desenvolvimento anormal do bulbo olfatório. Esses autores demonstraram ausência de neurônios secretores de GnRH no hipotálamo desses animais, confirman- 
do o papel do sistema Prok2/Prokr2 na neurogênese hipotalâmica (48). A maioria das mutações nos genes PROKR2 e PROK2 foi identificada em heterozigose em humanos, ocorrendo em pacientes com HHI com e sem anormalidades olfatórias. Contudo, Abreu e cols. (49), estudando um grande número de pacientes com síndrome de Kallmann e HHI normósmico, sugeriram que a haploinsuficiência dos genes PROKR2/PROK2 não seria suficiente para causar o fenótipo de hipogonadismo. De fato, um estudo recente realizado por Monnier e cols. (50) não mostrou evidências de um efeito dominante negativo dos receptores PROKR2 mutantes sobre o receptor tipo selvagem.

\section{Gene NELF}

O fator nasal embrionário do hormônio liberador de hormônio luteinizante (NELF) foi isolado pelo estudo comparativo da expressão diferencial de neurônios secretores de $\mathrm{GnRH}$ em migração e pós-embrionários em camundongos, sugerindo-se que este atua como uma molécula guia na projeção dos axônios olfatórios e na subsequente migração dos neurônios secretores de GnRH (Kramer, 2011). Em humanos, o gene NELF, formado por 16 éxons, foi mapeado em $9 \mathrm{q} 34$. Alguns trabalhos descrevem o achado de mutações no NELF em pacientes com síndrome de Kallman e HHI normósmico, contudo a importância desse gene no aparecimento da deficiência de GnRH em humano ainda é controversa $(41,51)$.

\section{Gene CHD7}

O gene CHD7 (chromodomain helicase DNA-binding protein 7) codifica uma proteína ligadora ao cromodomínio helicase do DNA. Esse gene, formado por 38 éxons e localizado em 8q12, está relacionado ao aparecimento da síndrome de CHARGE, uma síndrome caracterizada pela presença de coloboma, anomalias cardíacas, atresia de coanas, retardo do desenvolvimento, anomalias genitais e de ouvido (52). A hipótese de que o CHD7 estivesse envolvido na patogênese do hipogonadismo hipogonadotrófico foi considerada pela sobreposição de fenótipos entre as duas síndromes, em que o hipogonadismo muitas vezes está associado a alterações olfatórias (53). Assim, Kim e cols. (53) analisaram o gene CHD7 em 200 pacientes com deficiência isolada de gonadotrofinas e foram capazes de identificar mutações em três indivíduos com síndrome de Kallmann e quatro pacientes com hipogonadismo hipogonado- trófico normósmico (53). Em um estudo semelhante, Jongmans e cols. (54) sugeriram a investigação de fenótipos característicos da síndrome de CHARGE em pacientes com diagnóstico de hipogonadismo hipogonadotrófico, recomendando o estudo do gene CHD7 apenas naqueles casos em que tais fenótipos fossem evidenciados, particularmente surdez, dismorfismos do pavilhão auditivo e aplasia/hipoplasia dos canais semicirculares. $\mathrm{O} C H D 7$ não é expresso apenas nos órgãos associados à síndrome de CHARGE, mas também no epitélio olfatório, no hipotálamo e na hipófise, um padrão de expressão consistente com o envolvimento desse gene no desenvolvimento das estruturas olfatórias e dos neurônios secretores de GnRH (52).

\section{Gene HS6ST1}

As proteoglicanas sulfato de heparina estão presentes de forma ubíqua sobre a superfície celular e na matriz extracelular, interagindo com uma ampla gama de fatores e participando de vários processos, como crescimento, adesão e migração celulares $(55,56)$. A maioria das interações entre as proteoglicanas sulfato de heparina e seus ligantes (fatores de crescimento, receptores de superfície celular e proteases) ocorre em regiões específicas contendo modificações referentes ao grau e à posição da sulfatação, sendo as sulfotransferases as enzimas responsáveis por tal modificação (55-57). Uma dessas sulfotransferases, a 6-O-sulfotransferase de sulfato de heparina, foi capaz de suprimir a formação de rotas impróprias de migração causada pela superexpressão do gene kall em Caenorbabditis elegans, indicando que a anosmina-1 requer sulfato de heparina com sulfatação específica na posição 6-O para exercer propriamente suas funções (31).

O homólogo do gene em humanos, HS6ST1, é formado por dois éxons e está no cromossomo 2 q21. Esse gene foi considerado um candidato em potencial para a deficiência de GnRH. Tornberg e cols. (58) realizaram o escrutínio do HS6STI em 338 pacientes hipogonádicos, encontrando alterações gênicas (seis em heterozigose e uma em homozigose) em cinco casos com síndrome de Kallmann e dois outros com hipogonadismo hipogonadotrófico normósmico. Todas essas alterações foram localizadas em regiões proteicas altamente conservadas e levavam a uma atividade enzimática reduzida da 6-O-sulfotransferase sulfato de heparina in vitro e in vivo (58). Contudo, num contexto de interação com a proteína anosmina, foram observados diferentes 
graus de perda de função das proteínas HS6STl mutantes, indicando que a 6-O sulfotransferase de sulfato de heparina pode agir tanto por vias dependentes quanto independentes de anosmina-l (58). Esses resultados sugerem que a HS6STl e a complexa rede de modificações das glicosaminoglicanas extracelulares são críticas para o desenvolvimento normal dos neurônios secretores de GnHR em humanos. Interessantemente, a HS6STl age em conjunto com outros genes associados ao hipogonadismo hipogonadotrófico, como o FGFR I e o FGF8, consistente com o modelo de que a anosmina- $\mathrm{l}$ atua como uma molécula coligante ao FGF na ativação do FGFRl de maneira dependente de proteoglicanas sulfato de heparina $(42,43,58)$.

\section{Gene WDR11}

Mutações em heterozigose no gene WDR 11, o qual codifica uma proteína WD que interage com fator de transcrição EMXl, foram identificadas em seis pacientes com síndrome de Kallmann e HHI normósmico (59). Todas as alterações descritas induziram à remodelagem da proteína WDRlı, levando a redução ou eliminação de sua interação com o EMXl, interação essa crucial para a migração dos neurônios olfatórios (59). De fato, a análise de expressão do WDR 11 em células embrionárias olfatórias de humanos, camundongos e peixes zebrafish mostrou um padrão de expressão sobreposto com o fator de transcrição EMXI em regiões críticas para a formação do hipotálamo, sugerindo que tanto o EMXI quanto o WDR 11 são importantes para o desenvolvimento dos neurônios olfatórios (60).

Por outro lado, um estudo recente desenvolvido em uma casuística finlandesa não evidenciou nenhuma alteração no gene WDR 11 entre pacientes com HHI (61). Dessa forma, variações na sequência do WDR 11 apresentam um efeito causal direto sobre o fenótipo de HHI e síndrome de Kallmann em uma pequena proporção de casos, cerca de $3 \%$ dos pacientes com HHI estudados (59).

\section{DEFEITOS NA SÍNTESE E SECREÇÃo DE GnRH}

\section{Gene KISS1R}

Nos últimos anos, a kisspeptina bem como seu receptor KISS1R ou GPR54 foram considerados os principais reguladores do eixo reprodutivo. O gene KISSIR está localizado no cromossomo $19 \mathrm{pl} 3.3$ e codifica um receptor de membrana acoplado à proteína G. A ligação da kisspeptina ao KISS1R resulta na estimulação da via $\mathrm{G} \alpha \mathrm{q} / \mathrm{ll}$ e ativação da fosfolipase C, levando a um aumento na produção de trifosfato de inositol e na mobilização de cálcio intracelular. A kisspeptina é altamente expressa no núcleo arqueado e no núcleo periventricular anteroventral de roedores, enviando projeções para a área pré-óptica medial, na qual há abundância de neurônios secretores de GnRH. De fato, estudos fisiológicos e farmacológicos conduzidos em animais e humanos demonstraram que a kisspeptina é o mais potente estimulador da secreção de LH dependente de GnRH, identificado até o momento (62).

Em 2003, dois grupos de pesquisa independentes identificaram uma região cromossômica localizada no cromossomo 19, que segregou com o HHI em duas grandes famílias consanguíneas, por meio de estudos de ligação genética $(6,10)$. Após o rastreamento inicial de vários genes candidatos dessa região, mutações inativadoras no gene KISSIR foram identificadas em pacientes afetados, estabelecendo uma nova causa de HHI normósmico $(6,10)$. Análises de segregação familiar realizadas nessas famílias mostraram que os indivíduos portadores de alterações no gene KISSIR em heterozigose apresentavam um desenvolvimento puberal normal, confirmando um modelo de herança autossômica recessiva para essa doença. Mutações no KISSIR são consideradas uma causa rara de HHI, com uma frequência inferior a $5 \%$ em casos esporádicos $(1,6 \%)$, porém com uma frequência mais elevada entre os casos familiares $(20,8 \%)(6,10,63-65)$.

Os pacientes com mutações no gene KISSIR apresentam HHI sem alterações olfatórias ou outras condições clínicas associadas. $\mathrm{O}$ fenótipo reprodutivo desses indivíduos varia de hipogonadismo parcial a completo. De modo geral, o perfil neuroendócrino desses pacientes revela baixa amplitude dos pulsos de $\mathrm{LH}$, sugerindo uma secreção reduzida de GnRH $(10,65)$. É notável que tanto homens quanto mulheres portadores de mutações no KISSIR apresentam resultados satisfatórios no tratamento, seja ele realizado com a administração exógena de gonadotrofinas ou com infusão de GnRH pulsátil a longo prazo $(10,63,65,66)$. De fato, camundongos com ablação dos genes KISS1 e KISSIR não desenvolvem puberdade normal e exibem fenótipo de HHI, porém vale ressaltar que nesses animais os neurônios secretores de GnRH estão anatomicamente intactos e apresentam conteúdo normal de GnRH, sugerindo um papel na regulação da secreção de GnRH (66-69). 


\section{Genes TAC3/TACR3}

A neurocinina $B(\mathrm{NKB})$ é um peptídeo pertencente à família das taquicininas, a qual inclui substância $P$, neurocinina $\mathrm{A}$, hemocininas. $\mathrm{A} \mathrm{NKB}$ é codificada pelo gene $T A C 3$ e se liga a um receptor de membrana acoplado à proteína G denominado NK3R, o qual é codificado pelo gene TACR3. A ligação da NKB ao NK3R ativa diversas cascatas de sinalização intracelular, incluindo as vias de sinalização do fosfato de inositol e da fosfolipase C.

Uma ampla análise de SNPs pelo genoma humano realizada em nove famílias turcas consanguíneas, nas quais havia múltiplos membros com HHIn, levou à identificação de mutações inativadoras nos genes TAC3 e TACR3 em quatro famílias não relacionadas (11). Todos os pacientes com alterações no TAC3 e TACR3 apresentaram grave deficiência gonadotrófica; micropênis foi relatado em todos os pacientes, sugerindo falha no desenvolvimento intrauterino normal e na ativação perinatal do eixo reprodutivo (11). Em 2010, Gianetti e cols. (70) realizaram uma extensa análise dos genes TAC3 e TACR 3 em 345 indivíduos com HHIn, dos quais 60 eram brasileiros. Treze variantes raras no gene TACR3 foram descritas em 19 pacientes com HHI normósmico, sendo apenas uma anteriormente descrita, e uma nova variante no gene TAC3 em uma única paciente. Nesse trabalho foi verificado um alto índice de reversibilidade do quadro de HHIn na vida adulta, mesmo em pacientes com micropênis, sugerindo que a NKB poderia ter uma importância maior durante $o$ desenvolvimento neonatal, seguido de um efeito mais atenuado ao longo da vida do indivíduo (70).

Até o momento, cerca de 40 indivíduos com mutações nos genes TAC3 e TACR3 foram descritos, com uma ampla distribuição mundial e uma grande diversidade étnica (11,70-73). Mutações no complexo NKB/ NK3R são uma causa comum de HHIn, ocorrendo em mais de 5\% dos indivíduos com HHIn (70). No entanto, os mecanismos pelos quais a NKB exerce seus efeitos no controle central do eixo gonadotrófico ainda não foram estabelecidos.

\section{Gene GNRH1}

O gene que codifica o $\mathrm{GnRH}, G N R H 1$, foi por muitos anos considerado o candidato mais óbvio para a pesquisa de mutações em pacientes com distúrbios puberais de origem central, tais como em indivíduos com HHI. No entanto, apesar dos esforços na tentativa de identificar mutações nesse gene, apenas recentemente foram des- critas as primeiras alterações no GNRHI em pacientes com HHIn $(5,74)$. Bouligand e cols. (74) identificaram uma mutação em homozigose no GNRHI em um casal de irmãos com HHIn. A gravidade da deficiência gonadotrófica foi demonstrada por valores muito reduzidos de esteroides sexuais e de gonadotrofinas em ambos os indivíduos. Em outro recente estudo, a análise de 310 indivíduos com HHI normósmico revelou uma mutação em homozigose no GNRHI em um menino com HHI congênito grave e quatro mutações em heterozigose em quatro outros pacientes com HHI (5). No entanto, o real significado das mutações identificadas em heterozigose no gene GNRHI ainda não foi estabelecido.

Apesar do grande número de indivíduos rastreados até o momento, mutações no GNRHI parecem ser uma causa bastante rara de HHIn. Vale ressaltar que mutações de perda de função em proteínas ligantes tendem a ser menos frequentes que mutações nos seus receptores (5). Uma possibilidade para explicar essa diferença está relacionada ao tamanho do peptídeo ligante. O GNRHI, por exemplo, o qual contém apenas 10 aminoácidos na sua estrutura proteica final, representa um alvo "pequeno" para mutações. Além disso, a infertilidade devida à ocorrência de mutações genéticas resulta em um rápido desaparecimento desses defeitos herdados nas gerações futuras.

\section{RESISTÊNCIA AO GnRH}

\section{Gene GnRHR}

A ligação do GnRH ao seu receptor ativa diversas vias celulares de transdução de sinal, culminando na secreção das gonadotrofinas FSH e LH. Desde as primeiras alterações inativadoras descritas no receptor de $\mathrm{GnRH}$ (GnRHR) (7), muitas outras mutações foram descritas nos domínios extracelular, transmenbrana e intracelular do receptor, afetando, sobretudo, a ação do GnRH. O gene GNRHR está localizado no cromossomo $4 \mathrm{q} 13$ e codifica uma proteína de 328 aminoácidos. Esse receptor pertence à família dos receptores acoplados à proteína $\mathrm{G}$, porém difere de outros receptores dessa família por não apresentar o domínio citoplasmático carboxiterminal $(75,76)$.

Em 2001, Beranova e cols. (77) analisaram a frequência de mutações no gene GNRHR em 108 pacientes com HHI normósmico familial e esporádico. Nesse trabalho, a frequência de mutações no GNRHR 
foi de $40 \%$ entre os pacientes com HHI normósmico familial e de 16,7\% nos pacientes com a forma esporádica da doença, sendo considerada a causa mais frequente de HHI com herança autossômica recessiva (77). Ainda em 2001, Costa e cols. (78) identificaram duas mutações no GNRHR, uma em homozigose e outra em heterozigose composta. Nesse trabalho, observou-se uma boa correlação genótipo-fenótipo entre os pacientes brasileiros, visto que a paciente homozigota apresentou a forma completa de hipogonadismo hipogonadotrófico com valores basais indetectáveis de LH sem resposta ao estímulo com GnRH. Por outro lado, os pacientes com heterozigose composta, as quais inativavam parcialmente o receptor, apresentaram uma forma parcial de hipogonadismo hipogonadotrófico com valores basais reduzidos de $\mathrm{LH}$ responsivos ao estímulo com GnRH (78).

De forma geral, as mutações no gene GNRHR impedem ou reduzem a formação do complexo hormônio-receptor e estão associadas ao amplo espectro fenotípico apresentado por pacientes com HHI (78). Pacientes com mutações no GNRHR apresentam características clínicas que variam de HHI completo com criptorquidismo e ausência de desenvolvimento puberal a HHI parcial com desenvolvimento puberal incompleto (79). Além disso, a presença de ginecomastia foi evidenciada em cerca de $50 \%$ desses pacientes. Nas pacientes do sexo feminino com mutações no GNRHR, desenvolvimento puberal incompleto ou ausente, telarca incompleta e amenorreia primária seguida de uma baixa produção de estrógenos são as características clínicas mais frequentes (78).

Conclui-se que a lista crescente de genes envolvidos com a etiologia do hipogonadismo hipogonadotrófico congênito mostra a heterogeneidade e a complexidade da base genética dessa condição. Esses genes codificam peptídeos envolvidos com o desenvolvimento e migração dos neurônios $\mathrm{GnRH}$, ou com a regulação da síntese, secreção e ação desse hormônio. No entanto, apesar dos avanços das pesquisas genéticas nos últimos anos, a etiologia de grande parte dos casos de HHI permanece não estabelecida, sugerindo que ainda há muitas mutações a serem descobertas, as quais podem fornecer importantes informações acerca da organização e da regulação do eixo hipotálamo-hipófise-gonadal. A análise de DNA de famílias com HHI pode ser uma forma bastante promissora de identificar os novos candidatos gênicos relacionados a esses distúrbios. Ainda, com o avanço dos conhecimentos sobre a regulação genética e hormonal do eixo gonadotrófico, tornar-se-á fundamental integrar todos essas novas descobertas em um complexo sistema pulsátil, responsável pela regulação da puberdade e reprodução humana.

Declaração: os autores declaram não haver conflitos de interesse científico neste estudo.

\section{REFERÊNCIAS}

1. Palmert MR, Boepple PA. Variation in the timing of puberty: clinical spectrum and genetic investigation. J Clin Endocrinol Metab. 2001;86(6):2364-8.

2. Wray $S$, Grant $P$, Gainer $H$. Evidence that cells expressing luteinizing hormone-releasing hormone mRNA in the mouse are derived from progenitor cells in the olfactory placode. Proc Natl Acad Sci U S A. 1989;86(20):8132-6.

3. Schwanzel-Fukuda M, Pfaff DW. Origin of luteinizing hormone-releasing hormone neurons. Nature. 1989;338(6211):161-4.

4. Semple RK, Kemal Topaloglu A. The recent genetics of hypogonadotrophic hypogonadism - novel insights and new questions. Clin Endocrinol (Oxf). 2010;72(4):427-35.

5. Chan YM, de Guillebon A, Lang-Muritano M, Plummer L, Cerrato F, Tsiaras S, et al. GNRH1 mutations in patients with idiopathic hypogonadotropic hypogonadism. Proc Natl Acad Sci U S A. 2009;106(28):11703-8.

6. de Roux N, Genin E, Carel JC, Matsuda F, Chaussain JL, Milgrom E. Hypogonadotropic hypogonadism due to loss of function of the KiSS1-derived peptide receptor GPR54. Proc Natl Acad Sci U S A. 2003;100(19):10972-6.

7. de Roux N, Young J, Misrahi M, Genet R, Chanson P, Schaison G, et al. A family with hypogonadotropic hypogonadism and mutations in the gonadotropin-releasing hormone receptor. $\mathrm{N}$ Engl J Med. 1997;337(22):1597-602.

8. Dode C, Levilliers J, Dupont JM, De Paepe A, Le Du N, Soussi-Yanicostas N, et al. Loss-of-function mutations in FGFR1 cause autosomal dominant Kallmann syndrome. Nat Genet. 2003;33(4):463-5.

9. Dode C, Teixeira L, Levilliers J, Fouveaut C, Bouchard P, Kottler $M L$, et al. Kallmann syndrome: mutations in the genes encoding prokineticin-2 and prokineticin receptor-2. PLoS Genet. 2006;2(10):e175.

10. Seminara SB, Messager S, Chatzidaki EE, Thresher RR, Acierno JS Jr, Shagoury JK, et al. The GPR54 gene as a regulator of puberty. N Engl J Med. 2003;349(17):1614-27.

11. Topaloglu AK, Reimann F, Guclu M, Yalin AS, Kotan LD, Porter KM, et al. TAC3 and TACR3 mutations in familial hypogonadotropic hypogonadism reveal a key role for Neurokinin B in the central control of reproduction. Nat Genet. 2009;41(3):354-8.

12. Seminara SB, Oliveira LM, Beranova M, Hayes FJ, Crowley WF Jr. Genetics of hypogonadotropic hypogonadism. J Endocrinol Invest. 2000;23(9):560-5.

13. Silveira LF, Stewart PM, Thomas M, Clark DA, Bouloux PM, MacColl GS. Novel homozygous splice acceptor site $\mathrm{GnRH}$ receptor (GnRHR) mutation: human GnRHR "knockout". J Clin Endocrinol Metab. 2002;87(6):2973-7.

14. Oliveira LM, Seminara SB, Beranova M, Hayes FJ, Valkenburgh SB, Schipani $E$, et al.The importance of autosomal genes in Kallmann syndrome: genotype-phenotype correlations and neuroendocrine characteristics. J Clin Endocrinol Metab. 2001;86(4):1532-8.

15. Quinton R, Duke VM, Robertson A, Kirk JM, Matfin G, de Zoysa $\mathrm{PA}$, et al. Idiopathic gonadotrophin deficiency: genetic questions 
addressed through phenotypic characterization. Clin Endocrinol (Oxf). 2001;55(2):163-74.

16. Silveira LG, Abreu AP, Montenegro LR, Tusset $C$, Beneduzzi $D$, Castro $\mathrm{M}$, et al., editor. Congenital isolated hypogonadotropic hypogonadism: a detailed clinical and molecular characterization of a Brazilian patients cohort Endocrine Society's 93rd Annual Meeting; 2011; Boston, USA.

17. Tsang S. When size matters: a clinical review of pathological micropenis. J Pediatr Health Care. 2010;24(4):231-40.

18. Shaw ND, Seminara SB, Welt CK, Au MG, Plummer L, Hughes VA, et al. Expanding the phenotype and genotype of female $\mathrm{GnRH}$ deficiency. J Clin Endocrinol Metab. 2011;96(3):E566-76.

19. Mitchell AL, Dwyer A, Pitteloud N, Quinton R. Genetic basis and variable phenotypic expression of Kallmann syndrome: towards a unifying theory. Trends Endocrinol Metab. 2011;22(7):249-58.

20. Sykiotis GP, Plummer L, Hughes VA, Au M, Durrani S, Nayak-Young $\mathrm{S}$, et al. Oligogenic basis of isolated gonadotropin-releasing hormone deficiency. Proc Natl Acad Sci U S A. 2010;107(34):15140-4.

21. Grumbach MM. A window of opportunity: the diagnosis of gonadotropin deficiency in the male infant. J Clin Endocrinol Metab. 2005;90(5):3122-7.

22. Grumbach MM SD. Puberty: ontogeny, neuroendocrinology, physiology, and disorders. In: Larsen PR, Kronenberg HM, Melmed S, Polonsky KS, editors. Williams textbook of endocrinology 10th; 2003.

23. Bhasin S, Cunningham GR, Hayes FJ, Matsumoto AM, Snyder PJ, Swerdloff RS, et al. Testosterone therapy in men with androgen deficiency syndromes: an Endocrine Society clinical practice guideline. J Clin Endocrinol Metab. 2010;95(6):2536-59.

24. Raivio T, Falardeau J, Dwyer A, Quinton R, Hayes FJ, Hughes VA, et al. Reversal of idiopathic hypogonadotropic hypogonadism. N Engl J Med. 2007;357(9):863-73.

25. Ribeiro RS, Vieira TC, Abucham J. Reversible Kallmann syndrome: report of the first case with a KAL1 mutation and literature review. Eur J Endocrinol. 2007;156(3):285-90.

26. Schwanzel-Fukuda M, Bick D, Pfaff DW. Luteinizing hormone-releasing hormone (LHRH)-expressing cells do not migrate normally in an inherited hypogonadal (Kallmann) syndrome. Brain Res Mol Brain Res. 1989;6(4):311-26.

27. Franco B, Guioli S, Pragliola A, Incerti B, Bardoni B, Tonlorenzi R, et al. A gene deleted in Kallmann's syndrome shares homology with neural cell adhesion and axonal path-finding molecules. Nature. 1991;353(6344):529-36.

28. Legouis R, Hardelin JP, Levilliers J, Claverie JM, Compain S, Wunderle $\mathrm{V}$, et al. The candidate gene for the X-linked Kallmann syndrome encodes a protein related to adhesion molecules. Cell. 1991;67(2):423-35.

29. Rugarli El, Ballabio A. Kallmann syndrome. From genetics to neurobiology. JAMA. 1993;270(22):2713-6.

30. Duke VM, Winyard PJ, Thorogood P, Soothill P, Bouloux PM, Woolf AS. KAL, a gene mutated in Kallmann's syndrome, is expressed in the first trimester of human development. Mol Cell Endocrinol. 1995;110(1-2):73-9.

31. Bulow HE, Berry KL, Topper LH, Peles E, Hobert O. Heparan sulfate proteoglycan-dependent induction of axon branching and axon misrouting by the Kallmann syndrome gene kal-1. Proc Natl Acad Sci U S A. 2002;99(9):6346-51.

32. Robertson A, MacColl GS, Nash JA, Boehm MK, Perkins SJ, Bouloux PM. Molecular modelling and experimental studies of mutation and cell-adhesion sites in the fibronectin type III and whey acidic protein domains of human anosmin-1. Biochem J. 2001;357(Pt 3):647-59.

33. Rugarli El, Di Schiavi E, Hilliard MA, Arbucci S, Ghezzi C, Facciolli $A$, et al. The Kallmann syndrome gene homolog in C. elegans is involved in epidermal morphogenesis and neurite branching. Development. 2002;129(5):1283-94.
34. Soussi-Yanicostas N, de Castro F, Julliard AK, Perfettini I, Chedotal A, Petit C. Anosmin-1, defective in the X-linked form of Kallmann syndrome, promotes axonal branch formation from olfactory bulb output neurons. Cell. 2002;109(2):217-28.

35. Yanicostas C, Herbomel E, Dipietromaria A, Soussi-Yanicostas N. Anosmin-1a is required for fasciculation and terminal targeting of olfactory sensory neuron axons in the zebrafish olfactory system. Mol Cell Endocrinol. 2009;312(1-2):53-60.

36. Tsai PS, Gill JC. Mechanisms of disease: insights into X-linked and autosomal-dominant Kallmann syndrome. Nat Clin Pract Endocrinol Metab. 2006;2(3):160-71.

37. Trarbach EB, Silveira LG, Latronico AC. Genetic insights into human isolated gonadotropin deficiency. Pituitary. 2007;10(4):381-91.

38. Trarbach EB, Teles MG, Costa EM, Abreu AP, Garmes HM, Guerra $\mathrm{G} \mathrm{Jr}$, et al. Screening of autosomal gene deletions in patients with hypogonadotropic hypogonadism using multiplex ligation-dependent probe amplification: detection of a hemizygosis for the fibroblast growth factor receptor 1. Clin Endocrinol (Oxf). 2010;72(3):371-6.

39. Pitteloud N, Acierno JS Jr, Meysing A, Eliseenkova AV, Ma J, Ibrahimi $\mathrm{OA}$, et al. Mutations in fibroblast growth factor receptor 1 cause both Kallmann syndrome and normosmic idiopathic hypogonadotropic hypogonadism. Proc Natl Acad Sci U S A. 2006;103(16):6281-6.

40. Pitteloud N, Meysing A, Quinton R, Acierno JS Jr, Dwyer AA, Plummer $\mathrm{L}$, et al. Mutations in fibroblast growth factor receptor 1 cause Kallmann syndrome with a wide spectrum of reproductive phenotypes. Mol Cell Endocrinol. 2006;254-255:60-9.

41. Pitteloud N, Quinton R, Pearce S, Raivio T, Acierno J, Dwyer $A$, et al. Digenic mutations account for variable phenotypes in idiopathic hypogonadotropic hypogonadism. J Clin Invest. 2007;117(2):457-63.

42. Hu Y, Guimond SE, Travers P, Cadman S, Hohenester E, Turnbull $\mathrm{JE}$, et al. Novel mechanisms of fibroblast growth factor receptor 1 regulation by extracellular matrix protein anosmin-1. J Biol Chem. 2009;284(43):29905-20.

43. Gonzalez-Martinez D, Kim SH, Hu Y, Guimond S, Schofield J, Winyard $\mathrm{P}$, et al. Anosmin-1 modulates fibroblast growth factor receptor 1 signaling in human gonadotropin-releasing hormone olfactory neuroblasts through a heparan sulfate-dependent mechanism. J Neurosci. 2004;24(46):10384-92.

44. Meyers EN, Lewandoski M, Martin GR. An Fgf8 mutant allelic series generated by Cre- and Flp-mediated recombination. Nat Genet. 1998;18(2):136-41.

45. Falardeau J, Chung WC, Beenken A, Raivio T, Plummer L, Sidis $Y$, et al. Decreased FGF8 signaling causes deficiency of gonadotropin-releasing hormone in humans and mice. J Clin Invest. 2008;118(8):2822-31.

46. Trarbach EB, Abreu AP, Silveira LF, Garmes HM, Baptista MT, Teles $M G$, et al. Nonsense mutations in FGF8 gene causing different degrees of human gonadotropin-releasing deficiency. J Clin Endocrinol Metab. 2010;95(7):3491-6.

47. Chung WC, Moyle SS, Tsai PS. Fibroblast growth factor 8 signaling through fibroblast growth factor receptor 1 is required for the emergence of gonadotropin-releasing hormone neurons. Endocrinology. 2008;149(10):4997-5003.

48. Matsumoto S, Yamazaki C, Masumoto KH, Nagano M, Naito $M$, Soga $\mathrm{T}$, et al. Abnormal development of the olfactory bulb and reproductive system in mice lacking prokineticin receptor PKR2. Proc Natl Acad Sci U S A. 2006;103(11):4140-5.

49. Abreu AP, Trarbach EB, de Castro M, Frade Costa EM, Versiani B, Matias Baptista MT, et al. Loss-of-function mutations in the genes encoding prokineticin-2 or prokineticin receptor-2 cause autosomal recessive Kallmann syndrome. J Clin Endocrinol Metab. 2008:93(10):4113-8. 
50. Monnier C, Dode C, Fabre L, Teixeira L, Labesse G, Pin JP, et al. PROKR2 missense mutations associated with Kallmann syndrome impair receptor signalling activity. Hum Mol Genet. 2009;18(1):75-81.

51. Miura K, Acierno JS Jr, Seminara SB. Characterization of the human nasal embryonic LHRH factor gene, NELF, and a mutation screening among 65 patients with idiopathic hypogonadotropic hypogonadism (IHH). J Hum Genet. 2004;49(5):265-8.

52. Zentner GE, Layman WS, Martin DM, Scacheri PC. Molecular and phenotypic aspects of CHD7 mutation in CHARGE syndrome. Am J Med Genet A. 2010;152A(3):674-86.

53. Kim HG, Kurth I, Lan F, Meliciani I, Wenzel W, Eom SH, et al. Mutations in $\mathrm{CHD7}$, encoding a chromatin-remodeling protein, cause idiopathic hypogonadotropic hypogonadism and Kallmann syndrome. Am J Hum Genet. 2008;83(4):511-9.

54. Jongmans MC, van Ravenswaaij-Arts CM, Pitteloud N, Ogata T, Sato N, Claahsen-van der Grinten HL, et al. CHD7 mutations in patients initially diagnosed with Kallmann syndrome--the clinical overlap with CHARGE syndrome. Clin Genet. 2009;75(1):65-71.

55. lozzo RV, San Antonio JD. Heparan sulfate proteoglycans: heavy hitters in the angiogenesis arena. J Clin Invest. 2001;108(3):349-55.

56. Sugahara $\mathrm{K}$, Kitagawa $\mathrm{H}$. Recent advances in the study of the biosynthesis and functions of sulfated glycosaminoglycans. Curr Opin Struct Biol. 2000;10(5):518-27.

57. Habuchi O. Diversity and functions of glycosaminoglycan sulfotransferases. Biochim Biophys Acta. 2000;1474(2):115-27.

58. Tornberg J, Sykiotis GP, Keefe K, Plummer L, Hoang X, Hall JE, et al. Heparan sulfate 6-O-sulfotransferase 1 , a gene involved in extracellular sugar modifications, is mutated in patients with idiopathic hypogonadotrophic hypogonadism. Proc Natl Acad Sci U S A. 2011;108(28):11524-9.

59. Kim HG, Ahn JW, Kurth I, Ullmann R, Kim HT, Kulharya A, et al. WDR11, a WD protein that interacts with transcription factor EMX1, is mutated in idiopathic hypogonadotropic hypogonadism and Kallmann syndrome. Am J Hum Genet. 2011;87(4):465-79.

60. Schwarting GA, Wierman ME, Tobet SA. Gonadotropin-releasing hormone neuronal migration. Semin Reprod Med. 2007;25(5):305-12.

61. Laitinen EM, Vaaralahti K, Tommiska J, Eklund E, Tervaniemi M, Valanne $L$, et al. Incidence, phenotypic features and molecular genetics of kallmann syndrome in Finland. Orphanet J Rare Dis. 2011;6:41.

62. Irwig MS, Fraley GS, Smith JT, Acohido BV, Popa SM, Cunningham $\mathrm{MJ}$, et al. Kisspeptin activation of gonadotropin releasing hormone neurons and regulation of KiSS-1 mRNA in the male rat. Neuroendocrinology. 2004;80(4):264-72.

63. Lanfranco F, Gromoll J, von Eckardstein S, Herding EM, Nieschlag $\mathrm{E}$, Simoni M. Role of sequence variations of the GnRH receptor and $\mathrm{G}$ protein-coupled receptor 54 gene in male idiopathic hypogonadotropic hypogonadism. Eur J Endocrinol. 2005;153(6):845-52.

64. Semple RK, Achermann JC, Ellery J, Farooqi IS, Karet FE, Stanhope RG, et al. Two novel missense mutations in g protein-coupled receptor 54 in a patient with hypogonadotropic hypogonadism. J Clin Endocrinol Metab. 2005;90(3):1849-55.

65. Tenenbaum-Rakover Y, Commenges-Ducos M, lovane A, Aumas C, Admoni O, de Roux N. Neuroendocrine phenotype analysis in five patients with isolated hypogonadotropic hypogonadism due to a L102P inactivating mutation of GPR54. J Clin Endocrinol Metab. 2007;92(3):1137-44.
66. Colledge WH. Transgenic mouse models to study Gpr54/kisspeptin physiology. Peptides. 2009;30(1):34-41.

67. d'Anglemont de Tassigny X, Fagg LA, Dixon JP, Day K, Leitch $H G$, Hendrick AG, et al. Hypogonadotropic hypogonadism in mice lacking a functional Kiss1 gene. Proc Natl Acad Sci U S A. 2007;104(25):10714-9.

68. Funes S, Hedrick JA, Vassileva G, Markowitz L, Abbondanzo S, Golovko A, et al. The KiSS-1 receptor GPR54 is essential for the development of the murine reproductive system. Biochem Biophys Res Commun. 2003;312(4):1357-63.

69. Lapatto R, Pallais JC, Zhang D, Chan YM, Mahan A, Cerrato F, et al. Kiss1-/- mice exhibit more variable hypogonadism than Gpr54-/mice. Endocrinology. 2007;148(10):4927-36.

70. Gianetti E, Tusset C, Noel SD, Au MG, Dwyer AA, Hughes VA, et al. TAC3/TACR3 mutations reveal preferential activation of gonadotropin-releasing hormone release by neurokinin $B$ in neonatal life followed by reversal in adulthood. J Clin Endocrinol Metab. 2010;95(6):2857-67.

71. Fukami M, Maruyama T, Dateki S, Sato N, Yoshimura Y, Ogata T. Hypothalamic dysfunction in a female with isolated hypogonadotropic hypogonadism and compound heterozygous TACR3 mutations and clinical manifestation in her heterozygous mother. Horm Res Paediatr. 2010;73(6):477-81.

72. Guran T, Tolhurst G, Bereket A, Rocha N, Porter K, Turan S, et al. Hypogonadotropic hypogonadism due to a novel missense mutation in the first extracellular loop of the neurokinin B receptor. $J$ Clin Endocrinol Metab. 2009;94(10):3633-9.

73. Young J, Bouligand J, Francou B, Raffin-Sanson ML, Gaillez S, Jeanpierre $M$, et al.TAC3 and TACR3 defects cause hypothalamic congenital hypogonadotropic hypogonadism in humans. J Clin Endocrinol Metab. 2010;95(5):2287-95.

74. Bouligand J, Ghervan C, Tello JA, Brailly-Tabard S, Salenave S, Chanson $\mathrm{P}$, et al. Isolated familial hypogonadotropic hypogonadism and a GNRH1 mutation. N Engl J Med. 2009;360(26):2742-8.

75. Arora KK, Cheng Z, Catt KJ. Mutations of the conserved DRS motif in the second intracellular loop of the gonadotropin-releasing hormone receptor affect expression, activation, and internalization. Mol Endocrinol. 1997;11(9):1203-12.

76. Probst WC, Snyder LA, Schuster DI, Brosius J, Sealfon SC. Sequence alignment of the $\mathrm{G}$-protein coupled receptor superfamily. DNA Cell Biol. 1992;11(1):1-20.

77. Beranova M, Oliveira LM, Bedecarrats GY, Schipani E, Vallejo M, Ammini AC, et al. Prevalence, phenotypic spectrum, and modes of inheritance of gonadotropin-releasing hormone receptor mutations in idiopathic hypogonadotropic hypogonadism. J Clin Endocrinol Metab. 2001;86(4):1580-8.

78. Costa EM, Bedecarrats GY, Mendonca BB, Arnhold IJ, Kaiser UB, Latronico AC. Two novel mutations in the gonadotropin-releasing hormone receptor gene in Brazilian patients with hypogonadotropic hypogonadism and normal olfaction. J Clin Endocrinol Metab. 2001;86(6):2680-6.

79. Pralong FP, Gomez F, Castillo E, Cotecchia S, Abuin L, Aubert ML, et al. Complete hypogonadotropic hypogonadism associated with a novel inactivating mutation of the gonadotropin-releasing hormone receptor. J Clin Endocrinol Metab. 1999;84(10):3811-6. 